\title{
Birth Insult Alters Dopamine-Mediated Behavior in a Precocial Species, the Guinea Pig: Implications for Schizophrenia
}

\author{
Cathy Vaillancourt, Ph.D. and Patricia Boksa, Ph.D.
}

Schizophrenia is associated with increased birth complications, suggesting that birth complications might alter CNS dopaminergic activity later in life. In rats, Caesarean section (C-section) birth can produce long term changes in dopaminergic biochemistry and behavior. However rat brain is somewhat immature compared to human brain at birth. The current study tested if mild birth complications also alter dopamine-mediated function in a species with a more mature CNS at birth, the guinea pig. As adults, guinea pigs born by $C$-section showed increased amphetamine-induced locomotion and disruption of prepulse inhibition (PPI) of acoustic startle, compared to vaginally born controls. Guinea pigs born by C-section with
1 min of added global anoxia showed reduced amphetamineinduced locomotion and disrupted PPI, while a C-section plus 2 min anoxia group showed no change in amphetamine-induced locomotion but increased amphetamine-induced startle. No group differences in effects of amphetamine or apomorphine on PPI were observed. Taken with previous findings, these results indicate that mild birth complications can cause long term changes in dopamine-mediated behavior in both guinea pig and rat, two species spanning the level of human brain maturity at birth. [Neuropsychopharmacology 23:654-666, 2000] (C) 2000 American College of Neuropsychopharmacology. Published by Elsevier Science Inc.
KEY WORDS: Amphetamine; Caesarean section; Dopamine; Guinea pig; Locomotion; Perinatal hypoxia; Prepulse inhibition; Schizophrenia

There is considerable evidence that enhanced mesolimbic dopaminergic activity plays an important role in some of the symptomatology of schizophrenia (e.g., Laruelle et al. 1996, 1999; Breier et al. 1997; AbiDargham et al. 1998; see reviews by Seeman 1992; Lieberman et al. 1997). In addition, a large number of epidemiological studies have demonstrated that perinatal

From the Departments of Psychiatry and of Neurology and Neurosurgery, McGill University, Douglas Hospital Research Centre, Montreal, Quebec, Canada.

Address correspondence to: P. Boksa, Ph.D., Douglas Hospital Research Centre, 6875 LaSalle Blvd., Verdun, Quebec, Canada, H4H 1 R3.

Received 7 March 2000; revised 2 June 2000; accepted 17 June 2000. complications, often involving fetal or neonatal hypoxia, are associated with increased risk for the development of schizophrenia (e.g., Geddes and Lawrie 1995; Jones et al. 1998; Dalman et al. 1999; Hultman et al. 1999; Zornberg et al. 2000; see review by McNeil 1995).

Animal modelling provides the opportunity to directly test if a birth complication, such as hypoxia, can cause long term changes in dopaminergic function. Using a rat model of global hypoxia during Caesarean section (C-section) birth, several laboratories have demonstrated that dopaminergic systems are sensitive to mild birth alterations (Bjelke et al. 1991; Loidl et al. 1994; Chen et al. 1995, 1997; Brake et al. 1997a,b; El-Khodor and Boksa 1997, 1998; Vaillancourt and Boksa 1998; Berger et al. 2000a). Specifically, as adults, rats born by C-section, either with or without addition of a period of global hypoxia, show increased nucleus accumbens dopamine (DA) release in response to repeated stress (Brake et al. 1997b) and enhanced amphetamine 
(AMPH)-induced locomotion (El-Khodor and Boksa 1998) in comparison to vaginally born control rats. C-sectioned rats also show long term increases in DAD1 receptors and altered stress-induced regulation of D3 and D4 receptors (El-Khodor and Boksa, submitted). In this model, $\mathrm{C}$-section birth appears to produce very low grade respiratory alterations and CNS hypoxia during the first day of life (El-Khodor and Boksa 1997; Vaillancourt et al. 1999), similar to the reported increased incidence of mild respiratory distress in humans born by C-section (Hales et al. 1993).

In relation to the possible clinical relevance of these results, rat brain is generally believed to be somewhat less mature at birth than is the brain of the human newborn. It has been suggested that, at approximately postnatal day 10, the brain of the rat is at the stage of rapid growth, accelerated synaptogenesis, myelinization, and astrocyte proliferation characteristic of the human newborn at term (see review by Romijn et al. 1991). Thus, the model of birth insult in the rat may relate more to premature than to term human brain. To circumvent this limitation, we initiated the current studies to test if mild birth complications also alter DA mediated function in a species with a more mature CNS at birth. The guinea pig is a precocial species, that is, capable of a high degree of independent activity at birth. Compared to rat, guinea pig reaches neurobehavioral competence earlier and its brain is more fully developed at birth (Dobbing and Sands 1970; Douglas et al. 1973). For example, brain glycolytic enzymes are at adult levels in the newborn guinea pig but at low levels in rat brain at birth, whereas the human profile falls between these two species (Booth et al. 1980). Similarly, the period of rapid division of dentate granule cells occurs by 1 month of age in the rat but by 10 days in the guinea pig (Altman and Das 1965, 1967). Also, rapid maturation of EEG activity and traces reflecting active and quiet sleep appear in the guinea pig between day 50-56 of gestation (full gestation $=65-72$ days), at 35-37 weeks in the human (full gestation for term infant $=37-41$ weeks), and between postnatal days 10-13 in the rat (full gestation $=21-22$ days) (Dreyfus-Brisac 1970; Jouvet-Mounier et al. 1970; Gramsbergen 1976; Umans et al. 1985; see reviews by Prechtl 1974; Romijn et al. 1991).

We hypothesized that birth complications would produce long term changes in DA mediated function in species that span the level of maturity of human brain at birth, i.e., both rat and guinea pig. In the current study, we report our new findings on the more mature species, the guinea pig. For this study, guinea pigs were born vaginally, by C-section, or by C-section with addition of 1 or $2 \mathrm{~min}$ of global anoxia and were grown to adulthood. To test if these birth procedures affected DA function of relevance to schizophrenia, several behaviors were examined in these animals as adults. AMPHinduced locomotion was measured since behavioral and biochemical studies indicate that locomotion induced by low dose AMPH is most likely due to increased activity in the meso-accumbens DA pathway (e.g., Creese and Iversen 1975; Roberts et al. 1975; Costall et al. 1977; Porrino et al. 1984).

Acoustic startle responses (ASRs), prepulse inhibition (PPI) of the ASR and disruption of these by DA activating drugs, $\mathrm{AMPH}$, and apomorphine (APO), were also measured. PPI refers to an inhibition of the ASR when a low intensity prepulse precedes the startling pulse. PPI is reduced in schizophrenia and other psychiatric disorders such as obsessive compulsive and attention deficit disorders, and this reduction is thought to represent a deficiency in sensory gating in these disorders (see review by Swerdlow and Geyer 1998). PPI is regulated by dopaminergic mechanisms, being disrupted by enhanced mesolimbic DA activity (Mansbach et al. 1988, Swerdlow et al. 1990; Wan et al. 1994; Zhang et al. 2000; see review by Swerdlow and Geyer 1998). Recent evidence suggests that baseline PPI may also reflect DA tone as deficits in baseline PPI correlate with enhanced DA agonist induced locomotor responses in rats (Feifel 1999).

\section{METHODS}

All procedures with animals were performed in accordance with the guidelines of the Canadian Council on Animal Care and were approved by the McGill University Animal Care Committee.

\section{Guinea Pigs}

Guinea pigs were born by one of the four birth procedures outlined below and grown to adulthood (3 months of age) at which time behavioral testing was performed. Timed pregnant guinea pig dams were generated by in-house breeding. Nulliparous female Dunkin-Hartley guinea pigs (450-600 g; Charles River, St. Constant, Quebec, Canada) were bred with male Dunkin-Hartley guinea pigs. In brief, female guinea pigs were observed daily for rupture of the vaginal membrane, which indicates that the female is about to enter estrus. On rupture of their vaginal membranes, three females were housed in the presence of one male for three days. Following this, pregnant females were singly housed and membrane status and general health was monitored at least every week. Body weight was measured every two weeks. In the guinea pig, a vaginal plug is expelled a few hours after copulation and the vaginal membrane then reforms. Thus, day 0 of gestation was taken as the last day of full vaginal membrane opening. Gestation length for vaginally born control pups was 68-70 days and pups born by C-section (with or without anoxia) were also born at 68-70 days of gestation (i.e., the expected day of delivery.) 


\section{Birth Conditions}

C-Section Birth. On the expected day of delivery, the pregnant guinea pig was decapitated and immediately thereafter an abdominal incision was made and the uterus was quickly removed. (No maternal anesthetic was used in order to avoid possible respiratory depressant effects of anesthetic in the pups.) Pups were immediately delivered and breathing was stimulated by gentle tapping for a few sec. Time between sacrifice of the dam and delivery of the last pup in the litter was $<1$ min. The umbilical cord was ligated and pups placed on a heating pad (15-20 min) until placed with a surrogate mother. Survival rate at 3 months of age for animals born by C-section was $90 \%$.

C-Section Birth Plus 1 or 2 Minutes of Global Anoxia. Guinea pig pups underwent acute anoxia during C-section delivery using a procedure described for rats by Bjelke et al. (1991). On the expected day of delivery, the intact uterus containing pups was isolated from the dam via an abdominal incision as described above. Immediately thereafter, an acute anoxic episode was induced by immersing the isolated intact uterus containing pups into a $37^{\circ} \mathrm{C}$ saline bath for 1 or $2 \mathrm{~min}$. The uterus was removed from the bath and the pups delivered and stimulated by gentle tapping until breathing became even ( $30-40 \mathrm{sec}$ ); no other form of artificial resuscitation was used. Survival rates at 3 months of age for guinea pigs born by C-section +1 min anoxia or by $\mathrm{C}$-section +2 min anoxia were $99 \%$ and $56 \%$, respectively.

Quantitation of brain lactate, a marker of CNS hypoxia, and brain adenosine triphosphate (ATP) during the first $24 \mathrm{~h}$ of life, in a similar model of global birth anoxia in the rat indicates that this procedure produces consistent and reproducible CNS hypoxia in offspring (El-Khodor and Boksa 1997; Berger et al. 2000b). In the rat, 5 min of global birth anoxia significantly increases brain lactate and 10 min decreases brain ATP, whereas rat pups are able to survive 20-22 min of anoxia and begin breathing without artificial resuscitation. Because of the relative maturity of its CNS at birth, the guinea pig is able to survive much shorter periods of anoxia than is the rat (Jilek et al. 1970). Guinea pigs undergoing $>2 \mathrm{~min}$ of anoxia did not survive under our experimental conditions where no artificial resuscitation was employed. However 1-2 min of birth anoxia in the guinea pig may be considered a "moderate" degree of anoxia compared with the more severe (longer) anoxia that might be compatible with life if artificial resuscitation was employed.

Spontaneous Vaginal Birth. On the expected day of birth, guinea pig dams were observed regularly for birth of the first pup. On birth of the first pup, the dam was observed continuously and each pup was removed from the dam as soon as possible after natural vaginal birth $(<20 \mathrm{sec})$. Time from delivery of the first to the last pup in a single litter was about $20 \mathrm{~min}$. Pups were maintained on a heating pad, separate from their dams, as described above, until placed with surrogate dams at 20 min after birth. Survival rate at 3 months of age for animals born vaginally was $81 \%$, consistent with literature reports that high stillbirth rates are observed for primiparous guinea pigs (Ediger 1976).

Pups from each birth group were born from 4-5 separate dams, and there were no significant differences in average size of litters used to generate the four birth groups. There were no differences in birth weight among the pups born under the four different birth conditions indicating that pups born by $\mathrm{C}$-section were not premature. Birth weights (in $\mathrm{g} \pm \mathrm{SEM}, n=8$ ) were as follows: vaginal birth $=105.5 \pm 2.3$; C-section $=$ $104.8 \pm 1.1$; C-section +1 min anoxia $=105.8 \pm 2.5$; C-section +2 min anoxia $=105.5 \pm 1.9$.

Pups from all four birth groups were cross-fostered in litters of 3-4 pups/ surrogate dam. Surrogates were dams that had given birth vaginally on the same day as the experimental groups were generated. The surrogate dam's own pups remained with her until they were replaced with the foster litter; at this time the surrogate's original pups were sacrificed. Each foster litter contained a random mix of pups from the various birth groups (vaginal birth, C-section, C-section +1 min anoxia, C-section +2 min anoxia), to minimize differential rearing effects. A small quantity of indelible India ink was injected into one of the paws of each pup to identify animals from different birth groups and all pups were placed with the surrogate mother within 1520 min after birth. Pups were weaned at 15 days of age. Thereafter, males were separated from females and animals were group-housed (3-4 animals/cage) with lights on at 8:00 $\mathrm{h}$ and off at 20:00 $\mathrm{h}$ and with free access to Purina Guinea Pig Chow 5025 and water.

\section{Drugs}

Apomorphine hydrochloride (APO) was obtained from Research Biochemicals International (Natick, MA) and was dissolved in $0.9 \%$ saline $/ 0.1 \%$ ascorbic acid; d-amphetamine sulphate (AMPH) was from Sigma Chemical Co. (St. Louis, MO) and was dissolved in $0.9 \%$ saline. All injections were subcutaneous in a volume of $1 \mathrm{ml} / \mathrm{kg}$.

\section{Behavioral Testing}

At 3 months of age, eight guinea pigs (four males and four females) born under each of the four birth conditions (total number of animals $=32$ ) were tested for AMPH-induced motor activity. One month later, the same 32 animals were tested for baseline ASR and PPI of the ASR; two weeks after testing for baseline ASR/ PPI, all animals were tested for effects of saline, AMPH, 
and APO on ASR/PPI with an interval of 10 days between drug (or saline) treatments. Drug or saline treatments were administered in a counterbalanced order within each birth group to minimize carryover effects.

Motor Activity. Motor activity was monitored in a darkened room between 8:00 $\mathrm{h}$ and 17:00 $\mathrm{h}$ using activity chambers each equipped with two photoelectric switches. Light beam interruptions from each chamber were monitored and stored by computer. Animals were habituated to the apparatus for 2 days $(1 \mathrm{~h} /$ day $)$ prior to the experiment. On the day of the experiment, animals were placed in the activity boxes for recording $1 \mathrm{~h}$ of baseline activity, after which they received a subcutaneous injection of saline and activity was measured for a further $1 \mathrm{~h}$. Following this, $0.5 \mathrm{mg}$ of AMPH free base $/ \mathrm{kg}$ body weight was administered subcutaneously and activity was measured for an additional $3 \mathrm{~h}$. Data are expressed as photocell counts summed for each of 30 successive 10-min intervals ( $1 \mathrm{~h}$ baseline +1 $\mathrm{h}$ saline $+3 \mathrm{~h}$ AMPH recording $=300 \mathrm{~min}$ ).

Acoustic Startle Response and Prepulse Inhibition. Startle reactivity was measured using two SR-LAB startle response chambers (San Diego Instruments, San Diego, CA). Each sound-attenuated and ventilated chamber contained a Plexiglass cylinder, whose diameter $(12.6 \mathrm{~cm})$ allowed the animal to move but not to turn around. The cylinder was mounted atop a piezoelectric transducer, which detected vibrations caused by movement of the animal. An SR-LAB calibration unit was used to produce consistent response sensitivity between chambers and across days of testing. A sound generation system produced continuous background white noise at $70 \mathrm{~dB}$ and the required acoustic stimuli. Sound intensity within the chambers was calibrated using a Radio Shack digital sound level meter (A scale). A microcomputer control unit digitized and stored startle responses and also controlled timing and presentation of acoustic stimuli. Startle amplitude was defined as the average of 100 readings taken at 1 -msec intervals, beginning at stimulus onset.

Startle testing took place between 8:00 $\mathrm{h}$ and 17:00 $\mathrm{h}$. The startle session began with a 5-min acclimatization period in the presence of $70 \mathrm{~dB}$ background noise, that continued throughout the session. After this habituation period, the animals were presented with two orienting pulse alone trials $(120 \mathrm{~dB}, 30 \mathrm{msec})$; data from these two trials was discarded. Next, five blocks of trials were delivered. Each of these blocks consisted of the following eight trials: two pulse alone trials, five prepulse + pulse trials and one no-stimulus trial, in pseudo-random order. The pulse alone trial consisted of a $120 \mathrm{~dB}$ pulse for $30 \mathrm{msec}$. The five prepulse + pulse trials consisted of a 30-msec prepulse at 3, 6, 9, 12, or 15 $\mathrm{dB}$ above background followed by a 70-msec delay and then a startle pulse $(120 \mathrm{~dB}, 30 \mathrm{msec})$. The intertrial interval was an average $15 \mathrm{sec}$ (range 10-20 sec).

When testing for effects of drugs on PPI and ASR, guinea pigs received a subcutaneous injection of AMPH $(0.5 \mathrm{mg} / \mathrm{kg}), \mathrm{APO}(0.5 \mathrm{mg} / \mathrm{kg})$, or saline $10 \mathrm{~min}$ before being placed in the startle apparatus and tested for PPI and ASR using the protocol described above.

ASR was defined as the mean startle amplitude averaged from the 10 pulse alone trials. \%PPI was defined as [1 - (mean startle amplitude on prepulse + pulse trial) $/$ ASR) $] \times 100$.

\section{Data Analysis}

Data for motor activity were analyzed using two way analysis of variance (ANOVA) with birth condition as between-subject factor and time period as within-subject repeated measure. Data for baseline ASR were analyzed using one way ANOVA and data for effects of drugs on ASR were analyzed using two way ANOVA with birth condition as between-subject factor and drug treatment as within-subject repeated measure. Data for baseline PPI were analyzed using two way ANOVA with birth condition as between-subject factor and prepulse intensity as within-subject repeated measure. Data for effects of drugs on PPI were analyzed using three way ANOVA with birth condition as between-subject factor and drug treatment and prepulse intensity as within-subject repeated measures. Where appropriate, post hoc comparisons were conducted using Newman-Keuls tests. The accepted level of statistical significance $(\alpha)$ was $0.05 / 3=$ 0.016 to correct for multiple statistical analyses performed on three sets of behavioral data (motor activity, baseline ASR/PPI, and drug effects on ASR/PPI).

\section{RESULTS}

\section{Motor Activity}

Adult guinea pigs that had been born vaginally, by Csection, or by C-section with addition of 1 or $2 \mathrm{~min}$ of global anoxia, were administered saline or AMPH and motor activity was recorded (Figures 1A, B, and C). Data for male and female animals were combined for statistical analysis, since the patterns of AMPH responses observed for the two sexes were similar (Figures $1 \mathrm{~A}^{\prime}, \mathrm{B}^{\prime}$, and $\left.\mathrm{C}^{\prime}\right)$. Comparison of motor activity during the $60 \mathrm{~min}$ after saline injection vs. the $60 \mathrm{~min}$ after AMPH injection, for each birth group separately, indicated that motor activity was significantly stimulated by AMPH compared to saline in animals born vaginally $(p<.01)$, by C-section $(p<.0001)$, or by C-section with 2 min of anoxia $(p<.0029)$. In animals born by C-section +1 min of anoxia, motor activity was significantly reduced by AMPH compared to saline $(p<.0004)$. 


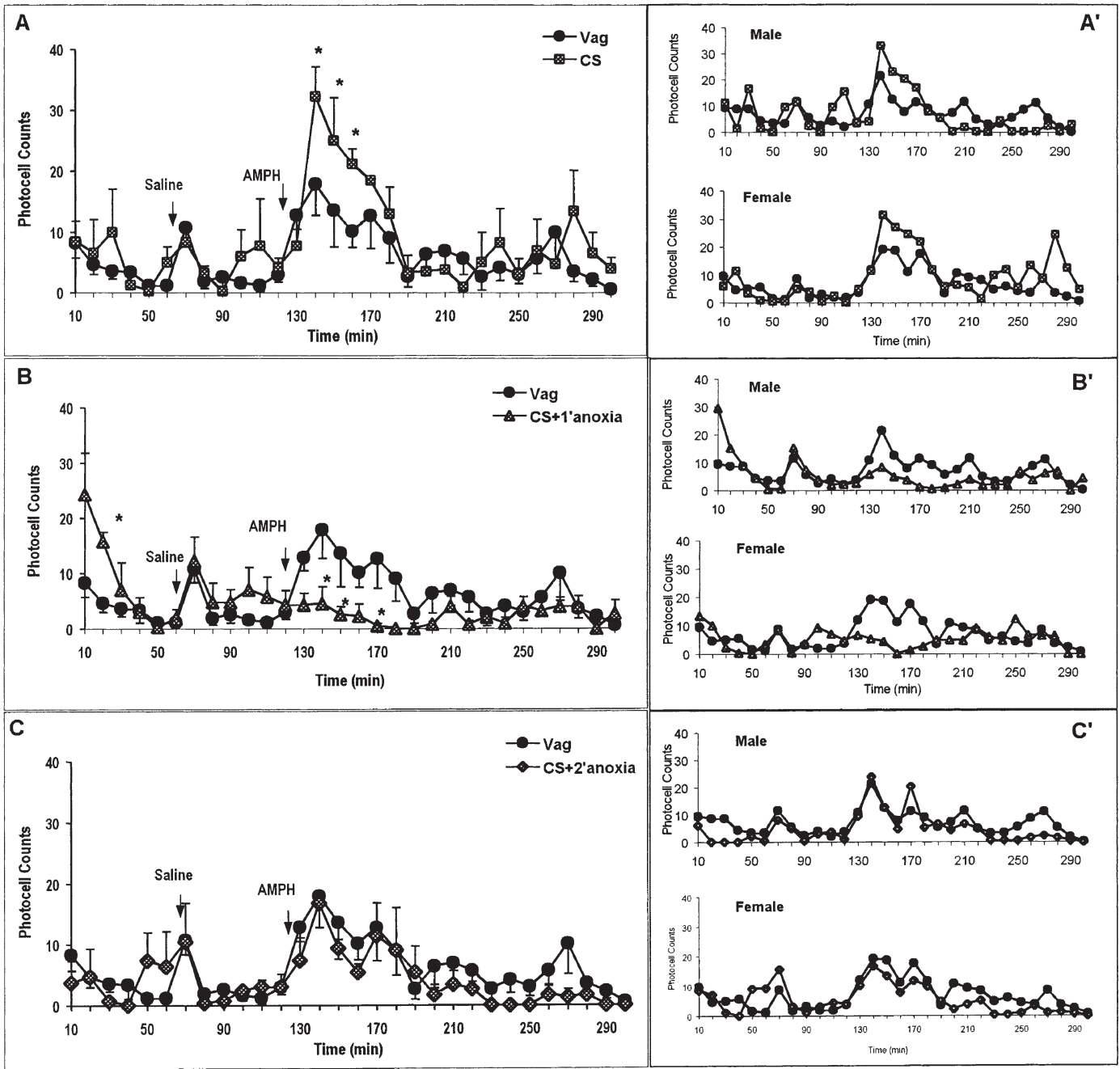

Figure 1. Motor activity following amphetamine administration to adult guinea pigs that had been born under various conditions. Guinea pigs were born vaginally (Vag), by C-section (CS) or by C-section with addition of 1 or 2 min of global anoxia (CS $+1^{\prime}$ anoxia; CS $+2^{\prime}$ anoxia). At 3 months of age, animals were placed in activity boxes for $1 \mathrm{~h}$ of baseline activity measurement after which they received subcutaneous injections of saline and activity was measured for $1 \mathrm{~h}$. Following this, d-amphetamine (AMPH, $0.5 \mathrm{mg} / \mathrm{kg}$ ) was administered subcutaneously and activity measured for an additional 3 h. A, B, and $\mathbf{C}$ show combined data for male and female animals (four female + four male $=$ eight animals/birth group), expressed as mean photocell counts $( \pm$ SEM) for each of 30 successive $10-$ min intervals. Data for vaginally born animals are repeated in each of the three panels, to facilitate comparison between birth groups. $\mathbf{A}^{\prime}, \mathbf{B}^{\prime}$, and $\mathbf{C}^{\prime}$ show separate data for male and female animals and are expressed as mean photocell counts. ${ }^{*} p<.015$ compared with the vaginally born control group.

Two way ANOVA of data for all four birth groups combined showed no overall effect of birth group $\left(\mathrm{F}_{3,16}=\right.$ $2.04, p=.1493)$, but a significant effect of time $\left(\mathrm{F}_{29,464}=\right.$ $5.28, p<.0001)$ and a significant birth group $\times$ time interaction $\left(\mathrm{F}_{87,464}=1.64, p=.0007\right)$. Compared to vaginally born controls, animals born by C-section showed significantly greater stimulation of motor activity at 2040 min after AMPH administration $(t=140-160 \mathrm{~min}$ in Figure 1A). By contrast, motor activity was significantly lower in animals born by $\mathrm{C}$-section +1 min anoxia in comparison to vaginally born controls at 20,30 , and 50 min after AMPH administration $(t=140,150$, and 170 in Figure 1B). Animals born by C-section +1 min anoxia also showed significantly enhanced motor activity compared to vaginal birth during the first $20 \mathrm{~min}$ of baseline activity on introduction to the locomotor apparatus $(\mathrm{t}=$ 10 and 20 in Figure 1B). Finally, AMPH-induced motor activity in animals born by $\mathrm{C}$-section +2 min anoxia was not significantly different from that measured in vaginally born controls (Figure 1C).

In addition to differences compared with vaginal birth, the C-section group showed significantly $(p<$ 
.015) enhanced motor activity compared to the C-section +1 min anoxia group at 20-50 min after AMPH administration $(\mathrm{t}=140-170 \mathrm{~min}$, compare Figures 1A and $1 \mathrm{~B}$ ) and compared to the $\mathrm{C}$-section +2 min anoxia group at 20-40 min after AMPH ( $\mathrm{t}=140-160$ min; Figures $1 \mathrm{~A}$ and $1 \mathrm{C}$ ).

Analyses of motor activity during the two days of habituation ( $1 \mathrm{~h} /$ day), prior to the test day with $\mathrm{AMPH}$, showed no effects of birth group (for day $1, \mathrm{~F}_{3,23}=0.52$, $p=.6741$; for day $\left.2, \mathrm{~F}_{3,23}=2.02, p=.1391\right)$ and no birth group $\times$ time interactions (for day $1, \mathrm{~F}_{15,115}=1.14, p=$ .3265 ; for day $2, \mathrm{~F}_{15,115}=0.72, p=.7585$ ), with motor activity expressed as photocell counts for each of 6 ten minute intervals on each habituation day (data not shown). Thus the motor activity of the four birth groups did not differ in response to initial exposure to the novel apparatus on these days.

\section{Acoustic Startle Response}

Figure 2A shows baseline ASR in adult guinea pigs born vaginally, by $\mathrm{C}$-section or by $\mathrm{C}$-section with anoxia. One

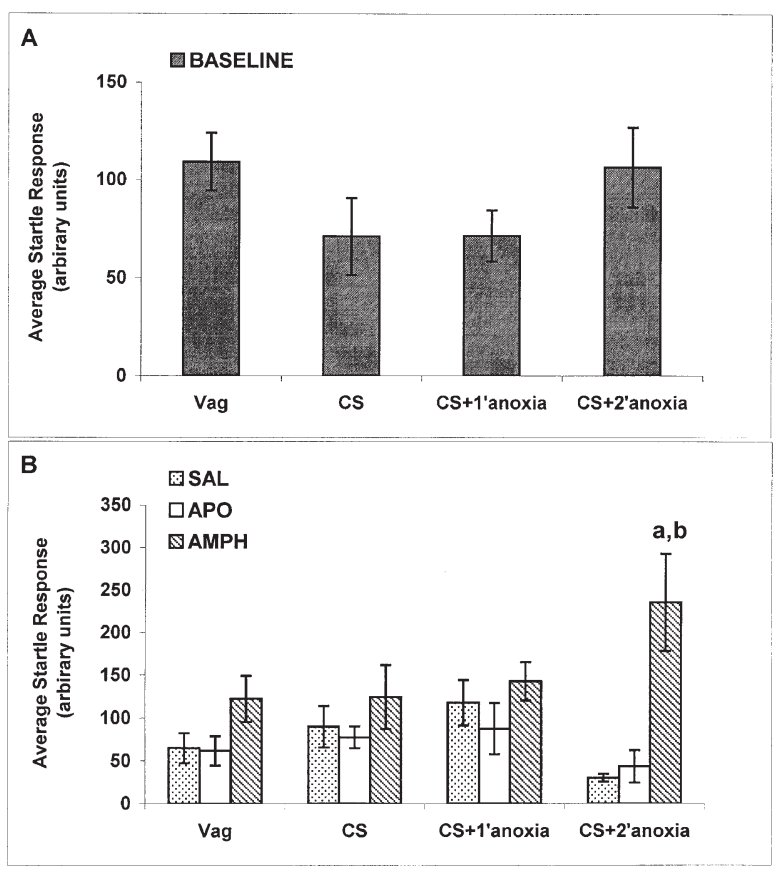

Figure 2. Acoustic startle responses in adult guinea pigs born under various conditions. A shows mean $( \pm$ SEM) startle amplitude produced by $120 \mathrm{~dB}$ pulses (in the absence of any prepulse) at baseline, and $\mathbf{B}$ shows acoustic startle amplitude after subcutaneous injection of saline (SAL), apomorphine (APO, $0.5 \mathrm{mg} / \mathrm{kg}$ ), or amphetamine $(\mathrm{AMPH}, 0.5 \mathrm{mg} / \mathrm{kg}$ ) in adult guinea pigs that were born vaginally (Vag), by C-section (CS), or by C-section with addition of 1 or 2 min of global anoxia (CS $+1^{\prime}$ anoxia; $C S+2{ }^{\prime}$ anoxia). ${ }^{a} p<.0001 \mathrm{vs.} \mathrm{SAL} \mathrm{or}$ $\mathrm{APO}$ for the CS $+2^{\prime}$ anoxia group; ${ }^{\mathrm{b}} p<.005 \mathrm{vs}$. AMPH for the vaginally born control group. way ANOVA indicated that baseline ASR did not differ among the four birth groups $\left(\mathrm{F}_{3,18}=1.38, p=.2799\right)$. Figure $2 \mathrm{~B}$ shows the effects of injections of saline, APO $(0.5$ $\mathrm{mg} / \mathrm{kg})$, or AMPH $(0.5 \mathrm{mg} / \mathrm{kg})$ on ASR in the same birth groups. Two way ANOVA showed no overall effect of birth group $\left(\mathrm{F}_{3,19}=0.42, p=.7438\right)$, but a significant effect of treatment $\left(\mathrm{F}_{2,38}=13.54, p<.0001\right)$ and a near significant birth group $\mathrm{x}$ treatment interaction $\left(\mathrm{F}_{6,38}=2.62, p=\right.$ .0317). Post hoc Newman-Keuls tests indicated that, in animals born by $\mathrm{C}$-section +2 min of anoxia, ASR after AMPH was greater than the response of this group after saline, and this difference was highly significant $(p<$ .0001). AMPH-induced ASR in the C-section + 2 min anoxia group was also greater than the AMPH response in vaginally born controls $(p<.005)$.

The low concentrations of APO and AMPH used had no significant effect (compared to saline) on ASR in vaginally born control guinea pigs. Similarly, in animals born by $\mathrm{C}$-section or by $\mathrm{C}$-section +1 min anoxia, APO and AMPH had no significant effect on ASR; ASRs after APO or AMPH were similar to saline in the same birth group and not significantly different from responses observed for vaginally born controls.

\section{Prepulse Inhibition of the Acoustic Startle Response}

Figure 3 shows baseline PPI in adult guinea pigs born vaginally, by $\mathrm{C}$-section, or by $\mathrm{C}$-section with anoxia. Results for male and female guinea pigs were combined since the pattern of results did not differ for the two sexes and studies in rats have demonstrated no sex difference in PPI of acoustic startle (Swerdlow et al. 1993). Two way ANOVA showed a near significant effect of birth group $\left(\mathrm{F}_{3,28}=2.72, p=.0634\right)$, a significant effect of prepulse intensity $\left(\mathrm{F}_{4,112}=130.60, p<.0001\right)$, and a significant birth group $\times$ prepulse intensity interaction $\left(\mathrm{F}_{12,112}=4.72, p<.0001\right)$.

Animals born by C-section showed a highly significant $(p<.0001)$ reduction in PPI, compared to vaginally born controls, at a prepulse intensity of $3 \mathrm{~dB}$ above background and reductions in PPI at $6 \mathrm{~dB}(p<.08)$ and $9 \mathrm{~dB}(p<.05)$ above background, that approached statistical significance. PPI was significantly reduced in animals born by $\mathrm{C}$-section +1 min anoxia compared to vaginal birth, at prepulse intensities of $6 \mathrm{~dB}(p<.001)$ and $9 \mathrm{~dB}(p<.005)$ above background.

\section{Effects of APO and of AMPH on PPI of the Startle Response}

The effects of APO (0.5 mg / kg) and of AMPH (0.5 mg/ $\mathrm{kg}$ ) on PPI in the various birth groups are shown in Figure 4. Three way ANOVA indicated significant main effects of drug treatment $\left(\mathrm{F}_{2,56}=19.10, p<.0001\right)$, of birth group $\left(\mathrm{F}_{3,28}=8.83, p=.0003\right)$, and of prepulse intensity 


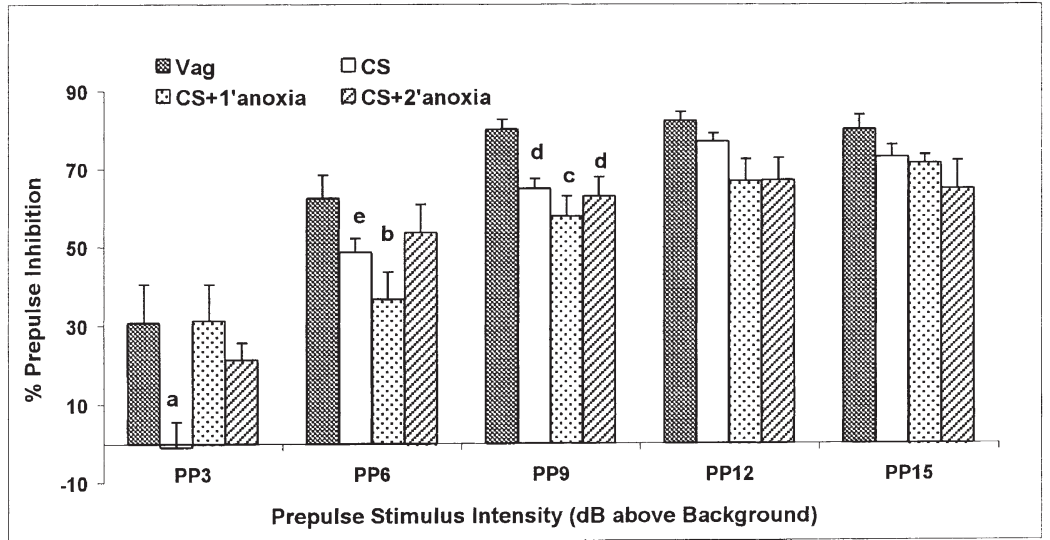

Figure 3. Prepulse inhibition of startle in adult guinea pigs born under various conditions. Data show the mean percentage ( \pm SEM) of prepulse inhibition produced at various prepulse (PP) intensities in adult guinea pigs that were born vaginally (Vag), by $\mathrm{C}$-section (CS), or by C-section with addition of 1 or 2 min of global anoxia (CS $+1^{\prime}$ anoxia; CS +2 ' anoxia). ${ }^{\text {a }} p<.0001 \mathrm{vs}$. Vag or $\mathrm{CS}+1^{\prime}$ anoxia, and $p<.005$ vs. CS $+2^{\prime}$ anoxia at the same prepulse intensity; ${ }^{\mathrm{b}} p<$ .001 vs. Vag at the same prepulse intensity; ${ }^{c} p<.005$ vs. Vag at the same prepulse intensity; ${ }^{\mathrm{d}} p<.05$ vs. Vag at the same prepulse intensity; ${ }^{\mathrm{e}} p<.08$ vs. Vag at the same prepulse intensity.
$\left(\mathrm{F}_{4,112}=121.10, p<.0001\right)$. However, there was no significant interaction between drug treatment $\times$ birth group $\left(\mathrm{F}_{6,56}=0.71, p=.6406\right)$ or between drug treatment $\times$ birth group $\times$ prepulse intensity $\left(\mathrm{F}_{24,224}=1.14\right.$, $p=.2973$ ), indicating that APO and AMPH had similar effects on PPI in all birth groups.

The only significant interaction was a drug treatment $\times$ prepulse intensity interaction $\left(\mathrm{F}_{8,224}=3.87, p=\right.$ .0003). Further analysis of this interaction indicated that both APO and AMPH significantly $(p<.01)$ reduced PPI relative to saline at all prepulse intensities; however, only at a prepulse of $3 \mathrm{~dB}$ above background (but not at the other prepulse intensities) APO inhibited PPI to a greater extent than did AMPH $(p<.01)$. The significant main effect of birth group was due to PPI being lower in the C-section +1 min anoxia group compared to all other birth groups, overall (i.e., under all drug treatments and at all prepulse intensities).

To further analyze if the magnitude of the reduction in PPI by APO (or AMPH) differed among the birth groups, PPI in the presence of APO (or AMPH) was expressed as a percent of PPI in the presence of saline for each birth group. For APO, two way ANOVA showed no effect of birth group $\left(\mathrm{F}_{3,30}=0.45, p=.7205\right)$ or of prepulse intensity $\left(\mathrm{F}_{4,120}=1.13, p=.3477\right)$, and no significant interaction $\left(\mathrm{F}_{12,120}=0.28, p=.9919\right)$, indicating that the magnitude of reduction of PPI produced by APO was similar in all birth groups and across all prepulse intensities. Similarly for AMPH, two way ANOVA showed no effect of birth group $\left(\mathrm{F}_{3,30}=1.25, p\right.$ $=.3086)$ or of prepulse intensity $\left(\mathrm{F}_{4,120}=0.12, p=.9762\right)$ and no significant interaction $\left(\mathrm{F}_{12,120}=0.60, p=.8348\right)$.

It is unclear why the reduction in PPI seen in the $\mathrm{C}$-section group at baseline is not evident after saline. Baseline testing was done on untreated animals receiving PPI testing for the first time. Since saline, APO and AMPH were subsequently administered in counterbalanced order, carryover effects from previous drug exposure, stress of repeated injections, or effects of re- peated testing may account for the differing profile in saline-treated versus untreated animals.

\section{DISCUSSION}

The main finding of this study is that in a precocial species, the guinea pig, mild birth complications (i.e., $\mathrm{C}$-section birth alone or C-section birth with a short added period of oxygen deprivation) can produce long term changes in DA-modulated behaviors. The pattern of changes differed somewhat according to the specific birth insult. Guinea pigs born by C-section showed enhanced AMPH-induced locomotion and reduced PPI of the ASR. In contrast, animals born by C-section $+1 \mathrm{~min}$ of anoxia showed reduced AMPH-induced locomotion and reduced PPI of the startle response, while those born by C-section +2 min of anoxia showed no change in AMPH-induced locomotion but an enhancement of AMPH-induced acoustic startle.

The mechanisms by which C-section birth alters behavior and why addition of brief global anoxia further alters the behavioral profile are not known. However, two factors likely to play a role are: 1) plasma hormone levels; and 2) the extent of hypoxia at birth.

Vaginal birth is associated with a surge in release of a wide variety of plasma hormones including catecholamines, glucocorticoids, and others, which serve to protect the neonate from hypoxia and promote adaptation to extrauterine life through priming of the lungs and other functions (for review see Lagercrantz 1994). Both humans and rats born by $\mathrm{C}$-section lack the catecholamine surge characteristic of a vaginal birth, and also have reduced levels of glucocorticoids in the neonatal period (Lagercrantz 1994; Boksa 1997; El-Khodor and Boksa 1997). These hormonal deficiencies may have direct effects on CNS development or predispose the C-sectioned neonate to mild respiratory distress. By contrast, a period of global hypoxia at birth serves as a 


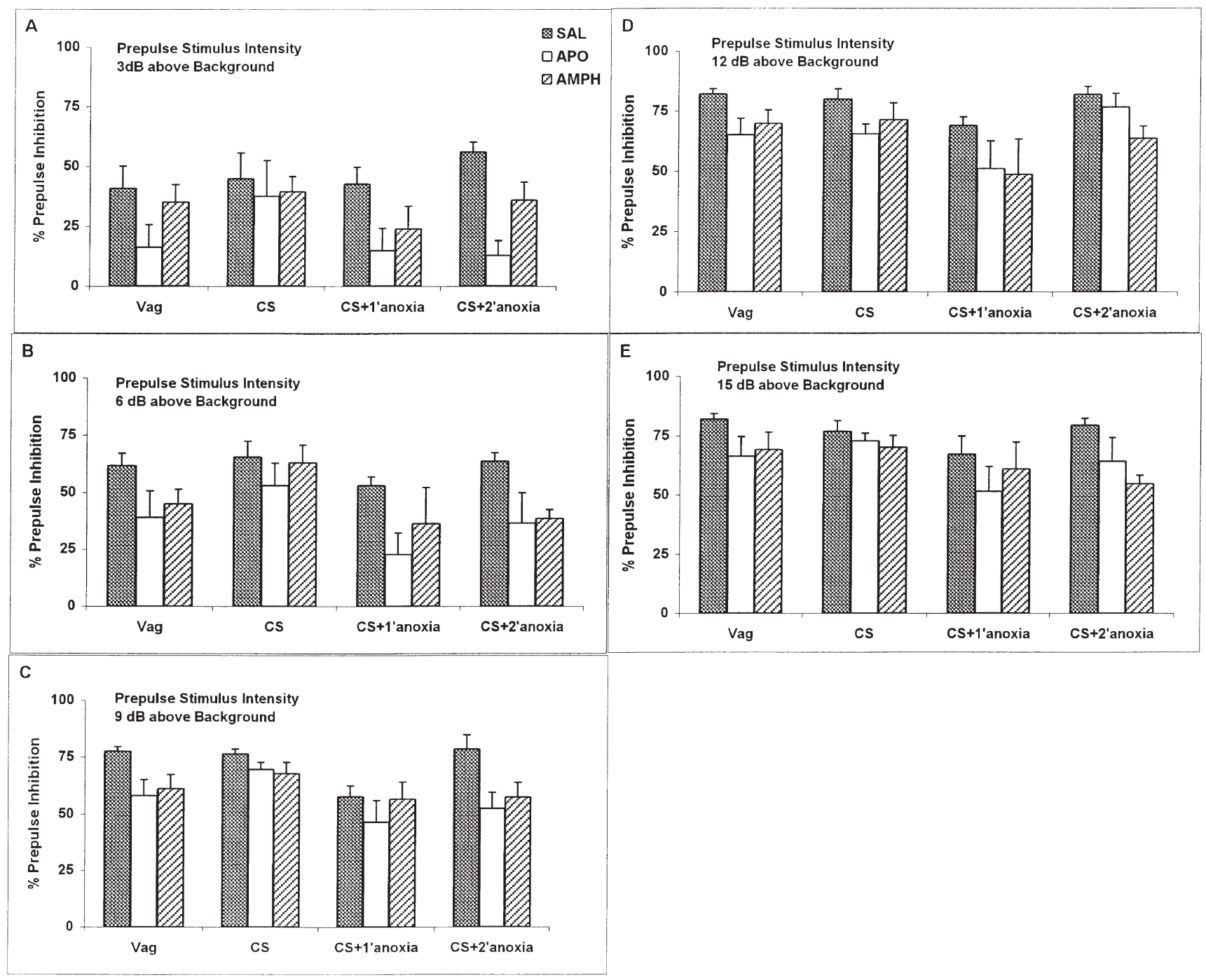

Figure 4. Effects of apomorphine and of amphetamine on prepulse inhibition of startle in adult guinea pigs born under various conditions. Adult guinea pigs that were born vaginally (Vag), by C-section (CS), or by C-section with addition of 1 or 2 min of global anoxia (CS $+1^{\prime}$ anoxia; $C S+2^{\prime}$ anoxia) received subcutaneous injections of saline (SAL), apomorphine $(\mathrm{APO}, 0.5 \mathrm{mg} / \mathrm{kg})$, or amphetamine (AMPH, $0.5 \mathrm{mg} / \mathrm{kg}) 10 \mathrm{~min}$ before testing for prepulse inhibition of the acoustic startle response. Data show the mean percentage ( \pm SEM) of prepulse inhibition produced at prepulse intensities of 3 (A), 6 (B), 9 (C), 12 (D), or $15 \mathrm{~dB}$ (E) above background noise (70 dB).

potent stimulus to plasma catecholamine release in both rats and humans, as well as activating central compensatory ventilatory responses (Seidler and Slotkin 1985; Lagercrantz 1994; El-Khodor and Boksa 1997).

In C-sectioned rats, systemic oxygenation and brain energy stores are well-maintained at birth, but later during the first $24 \mathrm{~h}$ of life, respiratory rates are altered and brain lactate slightly increased (El-Khodor and Boksa 1997; Vaillancourt et al. 1999). Thus, very low grade but prolonged hypoxia after C-section birth could contribute to later CNS changes. This parallels reports of increased mild respiratory distress (respiratory distress syndrome II) in C-sectioned human neonates (Hales et al. 1993). By contrast, rat pups undergoing a short period of global anoxia during C-section birth show rapid compensatory respiratory adaptation by $30 \mathrm{sec}$ after the anoxic episode and no further signs of respiratory distress during the first $24 \mathrm{~h}$ of life (El-Khodor and Boksa 1997; Vaillancourt et al. 1999; Berger et al. 2000b). In the present study, the different behavioral profiles among guinea pigs from various birth groups also likely relate to differential severity and time course of perinatal hypoxia, differential vulnerability of various brain regions to perinatal hypoxic insult, and differential recruitment of hormonal and other compensatory mechanisms.

It is well known that immature CNS is more resistant to hypoxia than is the mature CNS (Jilek et al 1970). Thus, in a model of C-section plus global anoxia similar 
to the one used in the current study, rat neonates are able to survive up to 20-22 min of added anoxia, without artificial resuscitation (Loidl et al. 1994; Boksa et al. 1995; Chen et al. 1995, 1997). However, guinea pigs survived only 2 min of birth anoxia due to the relative maturity of guinea pig CNS at birth. Given the sensitivity of neonatal guinea pigs to very short periods of oxygen deprivation, it is not surprising that a difference of 1 or 2 min of oxygen deprivation can produce differential behavioral effects.

Studies with the rat have indicated that alteration in perinatal maternal care, such as maternal separation for periods of $24 \mathrm{~h}$ or longer, can alter DA-mediated behavior in offspring (Zimmerberg and Shartrand 1992; Matthews et al. 1996; Rots et al. 1996). Thus, it is possible that differential maternal care might have influenced behavior in the various birth groups in the current study. Cross fostering in mixed litters does not eliminate the possibility that a given dam might care for individual members of the litter differentially with consequent effects on behavior. Further experiments with mixed versus homogenous litters may address this issue. However the guinea pig is a precocial species, born with open eyes, a high degree of neuromuscular coordination and neurobehavioral competence, and a full complement of fur, making it highly mobile and exploratory and capable of thermoregulation and independent feeding at birth. Thus, the guinea pig is much less likely to be affected by differential maternal care compared with the less mature rat at birth.

Locomotion induced by low doses of AMPH is thought to be mediated mainly by DA activity in the meso-accumbens DA pathway, based on studies employing lesions of DA pathways, pharmacological manipulation of DA and noradrenaline transmission, and metabolic mapping with 2-deoxyglucose (e.g., Creese and Iversen 1975; Roberts et al. 1975; Costall et al. 1977; Porrino et al. 1984).

The present study shows that in the guinea pig, AMPH-induced locomotion in the adult is sensitive to apparently rather subtle differences in birth condition. Animals born by C-section showed enhanced AMPHinduced locomotion. Addition of $1 \mathrm{~min}$ of anoxia to this birth procedure produced adults in which AMPH decreased locomotion while extending the period of birth anoxia to 2 min normalized AMPH-induced locomotion to a pattern similar to that for vaginally born controls. This contrasts with the rat model, where adult rats that had been born either by C-section or by C-section with 15 min of anoxia both showed enhanced AMPHinduced locomotion compared to vaginally born controls (El-Khodor and Boksa 1998; Vaillancourt and Boksa 1998). However, in the rat model also, some dopaminergic parameters altered by $\mathrm{C}$-section birth are normalized by addition of global anoxia. For example, rats born by $\mathrm{C}$-section showed long term changes in steady state DA levels in various brain regions and in D1 receptors and stress-induced regulation of D3 and D4 receptors, compared to vaginal birth (El-Khodor and Boksa 1997; El-Khodor and Boksa, submitted). However, these changes are normalized in rats born by C-section with addition of 10 or $15 \mathrm{~min}$ of anoxia. Thus, the simple assumption that addition of periods of global anoxia to a C-section birth should worsen CNS changes produced by $\mathrm{C}$-section alone is not supported by the experimental observations in these animal models.

In addition to increased AMPH-induced locomotion, guinea pigs born by C-section showed reduced baseline PPI of acoustic startle at low pre-pulse intensity, compared to vaginally born controls. This finding is of interest in relation to previous findings with animals and in humans with schizophrenia. Both locomotion and PPI of acoustic startle are strongly influenced by mesolimbic dopaminergic activation. Ellenbroek et al. (1995) have demonstrated that rats selected for enhanced locomotor responses to either novelty or APO have reduced baseline PPI, particularly at low prepulse intensities. In a similar vein, Feifel (1999) has recently demonstrated a negative correlation between APOinduced locomotion and PPI of acoustic startle among individual rats and has suggested that baseline PPI may serve as a measure of individual differences in DA tone. In C-sectioned guinea pigs, enhanced reactivity of mesolimbic dopaminergic pathways may be responsible for both the increased AMPH-induced locomotion and reduced PPI in these animals. These findings are reminiscent of findings in schizophrenia where patients exhibit reduced PPI of acoustic startle (see review by Swerdlow and Geyer 1998) and enhanced DA release from the striatum (Laruelle et al. 1996, 1999; Breier et al. 1997; Abi-Dargham et al. 1998).

In contrast to animals born by C-section alone, guinea pigs born by $\mathrm{C}$-section with $1 \mathrm{~min}$ of anoxia showed reductions in both AMPH-induced locomotion and PPI. While PPI is inhibited by overactivity of DA in the nucleus accumbens or anteromedial striatum, background evidence indicates that PPI is also regulated by circuitry involving cortical-striatal-pallidal and pontine relays and neurotransmission by glutamate, serotonin, GABA, and adenosine (Koch and Hauber 1998; see review by Swerdlow and Geyer 1998). Thus, altered function of some of these latter components may contribute to reduced PPI in the $1 \mathrm{~min}$ anoxia group, as well as in the C-section group. Future studies to delineate the neurochemical changes accompanying C-section birth \pm global anoxia in the guinea pig are warranted to address this issue. Information concerning neurochemical changes are available, however, from a similar model of birth hypoxia in the rat. In contrast to the long term changes in dopaminergic parameters already mentioned (Brake et al. 1997b; El-Khodor and Boksa 1997, 
1998;) (El-Khodor and Boksa, submitted), adult rats born by C-section with or without 15 min of added anoxia show no changes in levels of serotonin, 5-hydroxyindole acetic acid or norepinephrine in nucleus accumbens, striatum and prefrontal cortex, compared to vaginal birth (El-Khodor and Boksa 1997). Chen et al. (1997) have reported no change in levels of glutamate or aspartate in striatum, nucleus accumbens, ventral tegmental area and substantia nigra in 8-day-old rats that had been born by C-section with or without 2 to 22 min of anoxia. Additionally, 4-week-old rats born by C-section or by C-section with 20-21 min of anoxia showed no significant change in basal or $\mathrm{K}^{+}$-evoked glutamate or GABA release from the striatum, compared to vaginal birth, whereas basal glutamate release was decreased in rats born by C-section plus 21-22 $\mathrm{min}$ of anoxia (Chen et al. 1997). Thus, of the systems investigated in the rat model, dopaminergic systems appear to exhibit the greatest dysregulation compared to serotonin, glutamate, or GABA.

While guinea pigs in the various birth groups showed clear differences in AMPH-induced locomotor responses, AMPH (and APO) disrupted PPI in all birth groups and there was no difference in the magnitude of the disruption among birth groups. Mesolimbic DA activity has been implicated in the actions of dopaminergic agents in both behaviors, however a dissociation between effects of DA agonists on PPI vs. locomotion has been found in other studies in addition to the present one (see e.g., Kinney et al. 1999). AMPH may have differing effects on the two behaviors because subregions of the nucleus accumbens involved in modulation of the two behaviors may differ. For example, microinjection and lesion studies indicate that the nucleus accumbens shell rather than the core plays a predominant role in the locomotor stimulating effects of AMPH and DA agonists (Swanson et al. 1997; Parkinson et al. 1999). By contrast, DA agonist administration to either nucleus accumbens shell or core disrupts PPI, with a D2/D3 agonist producing a slightly greater effect in the core compared to the shell (Wan et al. 1994).

The only birth group to show changes in the ASR (without prepulse presentation) was the 2-min anoxia group in which enhanced AMPH-induced acoustic startle was observed. Previous studies with rats have shown that there is generally no correlation between changes in ASR and changes in PPI of the ASR (Swerdlow et al. 1990; Feifel 1999). Thus, the current study is not inconsistent with the literature in observing birth group differences in one of these parameters, PPI, but not the other, ASR. The ASR activates a pathway involving the cochlear nucleus, ventrolateral pons, reticular formation, and spinal motor neurons (reviewed by Yeomans and Frankland 1996). Reported effects of DAergic agents on acoustic startle have been inconsistent. For example, APO has been shown to decrease
(Swerdlow et al. 1994) or have no effect on ASR (Swerdlow and Geyer 1993; Feifel 1999), whereas AMPH increased ASR in some studies (Mansbach et al. 1988; Swerdlow et al. 1990) but not in others (Bakshi et al. 1995; Johannson et al. 1995). The observations that guinea pigs born by $\mathrm{C}$-section with $2 \mathrm{~min}$ of anoxia have increased ASR after AMPH, a catecholamine releasing drug, but not after APO, a D1/D2 agonist, would suggest an enhancement of pre-synaptic DAergic or noradrenergic mechanisms modulating ASR in these animals.

In conclusion, birth insult, consisting of C-section birth with or without addition of brief global anoxia, is sufficient to produce long-lasting alterations in DAmodulated behavioral responses in the guinea pig. Taken together with our previous studies in a rat model, these findings support the hypothesis that birth complications can produce long term changes in DAmediated function in two species that span the level of maturity of human brain at birth, i.e., rat and guinea pig. These findings suggest that the brain of the term human neonate may also be sensitive to subtle alterations in birth procedure, resulting in altered DAergic function later in life. This idea is consistent with epidemiological data showing increased incidence of birth complications among those developing disorders related to DA dysfunction, such as schizophrenia and attention deficit hyperactivity disorder. It should be emphasized that the model of birth insult used in the current study does not completely mimic all aspects of C-section birth or birth hypoxia as occurs in the human situation. However, further understanding of the precise factors (e.g., plasma hormone levels, pattern of birth hypoxia) responsible for alteration of DA-mediated behavior in these animal models of birth insult may allow one to determine if similar factors are present during any human birth procedures.

\section{ACKNOWLEDGMENTS}

This work was supported by a grant to PB from the Medical Research Council of Canada and a postdoctoral fellowship to CV from Fonds de la Recherche en Santé du Québec.

\section{REFERENCES}

Abi-Dargham A, Gil R, Krystal J, Baldwin RM, Seibyl JP, Bowers $M$, van Dyck $\mathrm{CH}$, Charney DS, Innis RB, Laruelle M (1998): Increased striatal dopamine transmission in schizophrenia: Confirmation in a second cohort. Am J Psychiatry 155:761-767

Altman J, Das GD (1965): Autoradiographic and histological evidence of postnatal hippocampal neurogenesis in rats. J Comp Neurol 124:319-336 
Altman J, Das GD (1967): Postnatal neurogenesis in the guinea pig. Nature 214:1098-1101

Bakshi VP, Geyer MA, Taaid N, Swerdlow NR (1995): A comparison of the effects of amphetamine, strychnine and caffeine on prepulse inhibition and latent inhibition. Behav Pharmacol 6:801-809

Berger N, Vaillancourt C, Boksa P (2000a): Genetic factors modulate effects of C-section birth on dopaminergic function in the rat. Neuroreport 11:645-649

Berger N, Vaillancourt C, Boksa P (2000b): Interactive effects of anoxia and general anesthesia during birth on the degree of CNS and systemic hypoxia produced in neonatal rats. Exp Brain Res 131:524-531

Bjelke B, Andersson K, Ögren SÖ, Bolme P (1991): Asphytic lesion: proliferation of tyrosine hydroxylase immunoreactive nerve cell bodies in the rat substantia nigra and functional changes in dopamine neurotransmission. Brain Res 543:1-9

Boksa P, Krishnamurthy A, Brooks W (1995): Effects of a period of asphyxia during birth on spatial learning in the rat. Pediatr Res 37:489-496

Boksa P (1997): Early developmental profiles of plasma corticosterone are altered by birth condition in the rat: A comparison of vaginal birth, Caesarean section and Caesarean section with added anoxia. Pediatr Res 41:34-43

Booth RFG, Patel TB, Clark JB (1980): The development of enzymes of energy metabolism in the brain of a precocial (guinea pig) and non-precocial (rat) species. J Neurochem 34:17-25

Brake WG, Boksa P, Gratton A (1997a): Effects of perinatal anoxia on the acute locomotor response to repeated amphetamine administration in adult rats. Psychopharmacology 133:389-395

Brake WG, Noel MB, Boksa P, Gratton A (1997b): Influence of perinatal factors on the nucleus accumbens dopamine response to repeated stress during adulthood: an electrochemical study in rat. Neuroscience 77:1067-1076

Breier A, Su T-P, Saunders R, Carson RE, Kolachana BS, de Bartolomeis A, Weinberger DR, Weisenfeld N, Malhotra AK, Eckelman WC, Pickar D (1997): Schizophrenia is associated with elevated amphetamine-induced synaptic dopamine concentrations: Evidence from a novel positron emission tomography method. Proc Natl Acad Sci U S A 94:2569-2574

Chen Y, Ögren SO, Bjelke B, Bolme P, Eneroth P, Gross J, Loidl F, Herrera-Marschitz M, Andersson K (1995): Nicotine treatment counteracts perinatal asphyxia-induced changes in the mesostriatal/limbic dopamine systems and in motor behavior in the four-week-old male rat. Neuroscience 68:531-538

Chen Y, Engidawork E, Loidl F, Dell'Anna E, Goiny M, Lubec G, Andersson K, Herrera-Marschitz M (1997): Short- and long-term effects of perinatal asphyxia on monoamine, amino acid and glycolysis product levels measured in the basal ganglia of the rat. Dev Brain Res 104:19-30

Costall B, Marsden CD, Naylor RJ, Pycock CJ (1977): Stereotyped behaviour patterns and hyperactivity induced by amphetamine and apomorphine after discrete 6-hydroxy- dopamine lesions of extrapyramidal and mesolimbic nuclei. Brain Res 123:89-111

Creese I, Iversen SD (1975): The pharmacological and anatomical substrates of the amphetamine response in the rat. Brain Res 83:419-436

Dalman C, Allebeck P, Cullberg J, Grunewald C, Köster M (1999): Obstetric complications and the risk of schizophrenia: A longitudinal study of a national birth cohort. Arch Gen Psychiatry 56:234-240

Dobbing J, Sands J (1970): Growth and development of the brain and spinal cord of the guinea pig. Brain Res $17: 115-123$

Douglas RJ, Peterson JJ, Douglas DP (1973): The ontogeny of a hippocampus-dependent response in two rodent species. Behav Biol 8:27-37

Dreyfus-Brisac C (1970): Oncogenesis of sleep in human prematures after 32 weeks of conceptional age. Dev Psychobiol 3:91-121

Ediger RD (1976): Care and management, Chap. II. Breeding, Sect. II. In Wagner JE, Manning PJ (eds), The Biology of the Guinea Pig. New York, Academic Press, pp 9-10

El-Khodor BF, Boksa P (1997): Long-term reciprocal changes in dopamine levels in prefrontal cortex versus nucleus accumbens in rats born by Caesarean section compared to vaginal birth. Exp Neurol 145:118-129

El-Khodor BF, Boksa P (1998): Birth insult increases amphetamine-induced behavioral responses in the adult rat. Neuroscience 87:893-904

Ellenbroek BA, Geyer MA, Cools AR (1995): The behavior of APO-SUS rats in animal models with construct validity for schizophrenia. J Neurosci 15:7604-7611

Feifel D (1999): Individual differences in prepulse inhibition of startle as a measure of individual dopamine function. Behav Neurosci 113:1020-1029

Geddes JR, Lawrie SM (1995): Obstetric complications and schizophrenia: A meta-analysis. Br J Psychiatry 167: 786-793

Gramsbergen A (1976): EEG development in normal and undernourished rats. Brain Res 105:287-308

Hales KA, Morgan MA, Thurnau GR (1993): Influence of labor and route of delivery on the frequency of respiratory morbidity in term neonates. Int J Gynecol Obstet 43:35-40

Hultman CM, Sparén P, Takei N, Murray RM, Cnattingius S (1999): Prenatal and perinatal risk factors for schizophrenia, affective psychosis, and reactive psychosis of early onset: Case-control study. Br Med J 318:421-426

Jilek L, Travnickova E, Trojan S (1970): Characteristic metabolic and functional responses to oxygen deficiency in the central nervous system. In Stave U (ed), Physiology of the Perinatal Period, Vol 2. Functional and Biochemical Development in Mammals. New York, AppletonCentury Crofts, Meredith Corp, pp 987-1041

Johannson C, Jackson DM, Zhang J, Svensson L (1995): Prepulse inhibition of acoustic startle, a measure of sensorimotor gating: Effects of antipsychotics and other agents in rats. Pharmacol Biochem Behav 52:649-654

Jones PB, Rantakallio P, Hartikainen A-L, Isohanni M, Sipila $P$ (1998): Schizophrenia as a long-term outcome of preg- 
nancy, delivery and perinatal complications: A 28 year follow-up of the 1966 North Finland general population cohort. Am J Psychiatry 155:355-364

Jouvet-Mounier D, Astic L, Lacote D (1970): Ontogenesis of states of sleep in rat, cat and guinea pig during the first postnatal month. Dev Psychobiol 2:216-239

Kinney GG, Wilkinson LO, Saywell KL, Tricklebank MD (1999): Rat strain differences in the ability to disrupt sensorimotor gating are limited to the dopaminergic system, specific to prepulse inhibition and unrelated to changes in startle amplitude or nucleus accumbens dopamine receptor sensitivity. J Neurosci 19:5644-5653

Koch M, Hauber W (1998): Regulation of sensorimotor gating by interactions of dopamine and adenosine in rat. Behav Pharmacol 1:23-29

Lagercrantz H (1994): Excitation of the sympatho-adrenal system at birth. In Amiel-Tison C, Stewart A (eds), The Newborn Infant, One Brain for Life. Paris, Les Editions INSERM, pp 57-66

Laruelle M, Abi-Dargham A, van Dyck CH, Gil R, D'Souza CD, Erdos J, McCance E, Rosenblatt W, Fingado C, Zoghbi SS, Baldwin RM, Seibyl JP, Krystal JH, Charney DS, Innis RB (1996): Single photon emission computerized tomography imaging of amphetamine-induced dopamine release in drug-free schizophrenic subjects. Proc Natl Acad Sci U S A 93:9235-9240

Laruelle M, Abi-Dargham A, Gil R, Kegeles L, Innis RB (1999): Increased dopamine transmission in schizophrenia: Relationship to illness phase. Biol Psychiatry 46:56-72

Lieberman JA, Sheitman BB, Kinon BJ (1997): Neurochemical sensitization in the pathophysiology of schizophrenia: Deficits and dysfunction in neuronal regulation and plasticity. Neuropsychopharmacology 17:205-229

Loidl CF, Herrera-Marschitz M, Andersson K, You Z-B, Goiny M, O'Connor WT, Silveira R, Rawal R, Bjelke B, Chen Y, Ungerstedt U (1994): Long-term effects of perinatal asphyxia on basal ganglia neurotransmitter systems studied with microdialysis in rat. Neurosci Lett 175:9-12

Mansbach RS, Geyer MA, Braff DL (1988): Dopaminergic stimulation disrupts sensorimotor gating in the rat. Psychopharmacology 94:507-514

Matthews K, Hall FS, Wilkinson LS, Robbins TW (1996): Retarded acquisition and reduced expression of conditioned locomotor activity in adult rats following repeated early maternal separation: Effects of prefeeding, d-amphetamine, dopamine antagonists and clonidine. Psychopharmacology 126:75-84

McNeil TF (1995): Perinatal risk factors and schizophrenia: Selective review and methodological concerns. Epidemiol Rev 17:107-112

Parkinson JA, Olmstead MC, Burns LH, Robbins TW, Everitt BJ (1999): Dissociation in effects of lesions of the nucleus accumbens core and shell on appetitive pavlovian approach behavior and the potentiation of conditioned reinforcement and locomotor activity by D-amphetamine. J Neurosci 19:2401-2411

Prechtl HFR (1974): The behavioral states of the newborn infant (a review). Brain Res 76:185-212

Porrino LJ, Lucignani G, Dow-Edwards D, Sokoloff L (1984):
Correlation of dose-dependent effects of acute amphetamine administration on behavior and local cerebral metabolism in rats. Brain Res 307:311-320

Roberts DCS, Zis AP, Fibiger HC (1975): Ascending catecholamine pathways and amphetamine-induced locomotor activity: Importance of dopamine and apparent non involvement of norepinephrine. Brain Res 93:441454

Romijn HH, Hofman MA, Gramsbergen A (1991): At what age is developing rat cortex comparable to that of the full term human baby? Early Human Dev 26:61-67

Rots NY, de Jong J, Workel JO, Levine S, Cools AR, De Kloet ER (1996): Neonatally maternally deprived rats have as adults elevated basal pituitary-adrenal activity and enhanced susceptibility to apomorphine. J Neuroendocrinol 8:501-506

Seeman P (1992): Dopamine receptor sequences: Therapeutic levels of neuroleptics occupy D2 receptors, clozapine occupies D4. Neuropsychopharmacology 7:261-284

Seidler FJ, Slotkin TA (1985): Adrenomedullary function in the neonatal rat: Responses to hypoxia. J Physiol 358:1-16

Swanson CJ, Heath S, Stratford TR, Kelley AE (1997): Differential behavioral responses to dopaminergic stimulation of nucleus accumbens subregions in the rat. Pharmacol Biochem Behav 58:933-945

Swerdlow NR, Auerbach P, Monroe SM, Hartston H, Geyer MA, Braff DL (1993): Men are more inhibited than women by weak prepulses. Biol Psychiatry 34:253-260

Swerdlow NR, Geyer MA (1993): Clozapine and haloperidol in an animal model of sensorimtor gating deficits in schizophrenia. Pharmacol Biochem Behav 44:741-744

Swerdlow NR, Geyer MA (1998): Using an animal model of deficient sensorimotor gating to study the pathophysiology and new treatments of schizophrenia. Schizophrenia Bull 24:285-301

Swerdlow NR, Mansbach RS, Geyer MA, Pulvirenti L, Koob GF, Braff DL (1990): Amphetamine disruption of prepulse inhibition of acoustic startle is reversed by depletion of mesolimbic dopamine. Psychopharmacology 100:413-416

Swerdlow NR, Zisook D, Taaid N (1994): Seroquel (ICI $204,636)$ restores prepulse inhibition of acoustic startle in apomorphine treated rats: Similarities to clozapine. Psychopharmacology 114:675-678

Umans JG, Cox MJ, Hinman DJ, Dogramajian ME, Senger G, Szeto HH (1985): The development of electrocortical activity in the fetal and neonatal guinea pig. Am J Obstet Gynecol 153:467-471

Vaillancourt C, Berger N, Boksa P (1999): Effects of vaginal birth versus Caesarean section birth with general anesthesia on blood gases and brain energy metabolism in neonatal rats. Exp Neurol 160:142-150

Vaillancourt C, Boksa P (1998): Caesarean section birth with general anesthesia increases dopamine-mediated behavior in the adult rat. Neuroreport 9:2953-2959

Wan FJ, Geyer MA, Swerdlow NR (1994): Accumbens D2 modulation of sensorimotor gating in rats: Assessing anatomical localization. Pharmacol Biochem Behav 49:155-163 
Yeomans JS, Frankland PW (1996): The acoustic startle reflex: neurons and connections. Brain Res Rev 21:301-314

Zhang J, Forkstam J, Engel A, Svensson L (2000): Role of dopamine in prepulse inhibition of acoustic startle. Psychopharmacology 149:181-188

Zimmerberg B, Shartrand AM (1992): Temperature-depen- dent effects of maternal separation on growth, activity and amphetamine sensitivity in the rat. Dev Psychobiol 25:213-226

Zornberg GL, Buka SL, Tsuang MT (2000): Hypoxicischemia related fetal/neonatal complications and risk of schizophrenia and other nonaffective psychoses: A 19 year longitudinal study. Am J Psychiatry 157:196-202 